\title{
Editorial
}

\section{Surveillance of Surgical-Site Infections: The World Coming Together?}

\author{
Robert P. Gaynes, MD
}

Surgical-site infections (SSIs) are associated with substantial risk of morbidity, resulting in prolongation of hospital stay and monetary costs attributable to the infection..$^{1-3}$ Reporting surgeon-specific SSI rates back to the surgeon has been shown in a number of studies to reduce SSI rates significantly, with appropriate cautions. ${ }^{47}$ Because of this, several countries have recently examined and reported their SSI experience. ${ }^{813}$ This issue of the Journal brings another article for consideration..$^{14}$ This article describes the first year of the Dutch national surveillance of SSIs and risk factors. The results, while preliminary, show many of the same findings seen in other studies:

- There are multiple risk factors for SSIs. The Dutch study found age, preoperative length of stay, wound class, anesthesia score, and duration of surgery to be independently important risk factors for SSIs when all procedures were pooled together for analysis.

- Risk factors vary by procedure. The nature and relative importance of the risk factors differed when individual procedures were examined in the Dutch PREZIES (Preventie van Ziekenhuisinfecties door Surveillance [Prevention of Nosocomial Infections Through Surveillance]) Project.

- SSIs are very costly to the healthcare system. The Dutch study found an attributable increased length of stay of 8.2 days for patients with SSIs. In any nation, an additional week or so of hospitalization is expensive.

It should not be surprising that so many countries are attempting to monitor this infection. However, the efforts of Geubbels and colleagues point out the difficulties with which all countries struggle in doing so. These include monitoring a national representation based upon a probability sampling of procedures; cooperation of hospitals and, in particular, surgeons; adequate sample size for certain surgical procedures; accuracy of data, especially with regard to postdischarge surveillance; and, ultimately, validity of comparisons with other SSI rates.

Despite the difficulties, the Dutch study specifically points out the feasibility of such a surveillance system. The study also confirmed that many of the risk factors from the Basic SSI Risk Index used in the Centers for Disease Control and Prevention (CDC)'s National Nosocomial Infections Surveillance (NNIS) System were risk factors in The Netherlands. Further, there was close correlation of the 75th percentile of duration of surgery between the Dutch system and the NNIS system for similar group procedures. In general, if differences existed, they were minor, with the NNIS durations tending to be longer (Table). The differences may be due simply to smaller sample size and thus poorer estimates for the 75th percentiles in the PREZIES Network compared to the NNIS System; the distributions of the specific ICD-9 codes may have been different for the procedures (which are grouped codes in both systems); the actual measure of duration of surgery may have differed slightly between The Netherlands and the United States; or Dutch surgeons may have been slightly faster at operating. The reasons for the differences in duration of surgery are not any clearer than the reasons for differences in the SSI rates. Thus, even for the simplest of variables, duration of surgery, comparisons across surveillance systems are difficult; only where enormous differences occur can conclusions be drawn. For example, a comparison of surveillance systems for SSIs in Belgium and The Netherlands found an extraordinary difference in the use of antimicrobial prophylaxis for herniorrhaphies (3.7\% in The Netherlands vs $41.9 \%$ in Belgium) ${ }^{15}$ This observation led directly to closer examination of antimicrobial prophylaxis in Belgium. ${ }^{16}$

More recently, at the 4 th Decennial International Conference on Nosocomial and Healthcare-Associated 
TABLE

Comparisons of THE 75Th Percentile of the Duration of SURGERY From the DUTCH PREZIES NATIONAL NETWORK AND tHE National Nosocomtal InfECtions SurveillanCE System, BY SELECTED PROCEDURES

\begin{tabular}{lcc}
\hline & $\begin{array}{c}\text { PREZIE } \\
\text { Network } \\
\text { 75th }\end{array}$ & $\begin{array}{c}\text { NNIS } \\
\text { System }\end{array}$ \\
& $\begin{array}{c}\text { Percentlle } \\
\text { Duration } \\
\text { of Surgery }\end{array}$ & $\begin{array}{c}\text { 75th } \\
\text { Percentlle } \\
\text { Duration } \\
\text { of Surgery } \\
\text { (min) }\end{array}$ \\
Procedure & 60 & 60 \\
\hline Cesarean section & 115 & 120 \\
Mastectomy & 45 & 60 \\
Appendectomy & 90 & 120 \\
Abdominal hysterectomy & 90 & $95^{\star}$ \\
Laparoscopic cholecystectomy & 135 & 180 \\
Colon surgery & 85 & 120 \\
Herniorrhaphy & 85 & 120 \\
Vaginal hysterectomy & &
\end{tabular}

Abbreviations: NNIS, National Nosocomial Infections Surveillance; PREZIES, Preventie van Ziekenhuisinfecties door Surveillance [Prevention of Nosocomial Infections Through Surveillance] Project.

* Unpublished NNIS data, 1997-1999.

Infections, a number of countries presented preliminary findings from surveillance systems for SSIs. Many of the systems confirmed the findings above, including the multiple nature of risk factors for SSIs and the differences in risk factors by procedure. Typically, although many of the factors in the Basic NNIS SSI Risk Index were included, the relative weights differed among the systems presented. None of these results is very surprising. What may be more noteworthy are the methods used by these diverse systems. Computer software has aided systems in France and Germany. Data collection is used with computerized scanning technology in Northern Ireland and with palm computing platforms in Australia. Statistical process control charts are used for data analysis in Argentina and Brazil. Multivariate analyses of data from a variety of the SSI surveillance systems were presented at the conference, and different relative weights were found of risk factors for SSIs in nearly all cases. ${ }^{17}$ As reported recently, these analyses cast a large shadow on the continued use of the Basic NNIS SSI Risk Index, in which all of the factors are equally weighted. ${ }^{18}$

Where is this all leading? The rapid development of SSI surveillance in so many countries will lead either to convergence or divergence of the approaches. Recommending converging is easy; achieving it will be difficult. The advantage of converging approaches is that the findings from one system can confirm those of a similar system, thus lending credibility to both systems. Lessons in converging approaches can be learned from countries in the European
Union. ${ }^{19}$ The process will be hard, but may be made easier by Internet technology that will allow communications and even data to cross borders far easier than we have seen in the 20th century. The benefit to all will be reductions in rates of SSIs, which currently cause such tragic worldwide consequences.

\section{REFERENCES}

1. Brachman PS, Dan BB, Haley RW, Hooton TM, Garner JS, Allen JR. Nosocomial surgical infections: incidence and cost. Surg Clin North Am 1980;60:15-25.

2. Poulsen KB, Bremmelgaard A, Sorensen AI, Raahave D, Petersen JV. Estimated costs of postoperative wound infections. A case-control study of marginal hospital and social security costs. Epidemiol Infect 1994;113:283-295.

3. Vegas AA, Jodra VM, Garcia ML. Nosocomial infection in surgery wards: a controlled study of increased duration of hospital stays and direct cost of hospitalization. Eur J Epidemiol 1993;9:504-510.

4. Altemeier WA, Culbertson WR. Surgical infection. In: Moyer CA, Rhoads JE, Allen JG, Harkins HN, eds. Surgery, Principles and Practice. Philadelphia, PA: JB Lippincott; 1965:51-77.

5. Haley RW, Culver DH, White JW, Morgan WM, Emori TG, Munn VP, et al. The efficacy of infection surveillance and control programs in preventing nosocomial infections in US hospitals. Am J Epidemiol 1985;121:182-205.

6. Scheckler WE. Surgeon specific wound infection rates-a potentially dangerous and misleading strategy. Infect Contol Hosp Epidemiol 1988:9:145-146.

7. Consensus paper on the surveillance of surgical wound infections. The Society for Hospital Epidemiology of America; the Association for Practitioners in Infection Control; the Centers for Disease Control and Prevention; the Surgical Infection Society. Infect Control Hosp Epidemiol 1992;20:263-270.

8. Simchen E, Wax Y, Pevsner B, Erdal M, Michel J, Modan M, et al. The Israeli Study of Surgical Infections (ISSI), I: methods for developing a standardized surveillance system for a multicenter study of surgical infections. Infect Control Hosp Epidemiol 1988;9:232-240.

9. Ronveaux O, Mertens R, Dupont Y. Surgical wound surveillance: results from the Belgium hospital network. Acta Chir Belg 1996;96:3-10.

10. Kjaeldgaard P, Cordtz T, Sejberg D, Kjaersagaard E, Silleman MP, La Cour Andersen J, et al. The DANOP-DATA system: a low-cost personal computer based program for monitoring of wound infections. $J$ Hosp Infect 1989;13:273-279.

11. Gulacsi L, Kiss ZT, Dovacs A, Vass L, Lukacs Toth G, Bessenyei L, et al. Uncomplicated wound healing, part 6: hospital wound infection surveillance program in Hungarian hospitals, 1992-1994. Health Management Rev 1996;5:432-449.

12. Severijnen AJ, Verbrugh HA, Mintjes de Groot AJ, Vanderbrouke-Grauls CMJE, van Pelt W. Sentinel system for nosocomial infections in The Netherlands: a pilot study. Infect Control Hosp Epidemiol 1997;18:818824.

13. National Nosocomial Infections Surveillance (NNIS) report, data summary from October 1986-April 1997, issued May 1997. A report from the NNIS System. Am I Infect Control 1997;25:477-487.

14. Geubbels ELPE, Mintjes-de Groot AJ, van den Berg JMJ, de Boer AS. An operating surveillance system of surgical-site infections in The Netherlands: results of the PREZIES National Surveillance Network. Infect Control Hosp Epidemiol 2000;21:311-318.

15. Mertens R, Van de Berg JM, Veerman-Brenzikofer MLV, Kurz X, Jans B, Klazinga $C$. International comparison of results of infection surveillance: The Netherlands versus Belgium. Infect Controi Hosp Epidemiol 1994;15:574-580.

16. Kurz X, Mertens R, Ronveaux $O$. Antimicrobial prophylaxis in surgery in Belgian hospitals: room for improvement. Eur J Surg 1996;162:15-21.

17. Morikane K, Nishioka M, Konishi T, Ohkubo T, Kusachi N, Umeta S, et al. Initiation of nation-wide nosocomial infection surveillance in Japan. Infect Control Hosp Epidemiol 2000;21:156. Abstract.

18. Gaynes RP. Surgical-site infections and the NNIS SSI risk index: room for improvement. Infect Control Hosp Epidemiol 2000;21:184-185.

19. Jepsen OB. Towards European Union standards in hospital infection control. J Hosp Infect 1995;30(suppl):64-68.

20. Culver DH, Horan TC, Gaynes RP, Martone WJ, Jarvis WR, Emori TG, et al. Surgical wound infection rates by wound class, operative procedure, and patient risk index. National Nosocomial Infection Surveillance System. Am J Med 1991;91 (suppl 3B):152S-157S. 